\title{
Brain stem death and organ donation
}

\author{
A Bodenham, J C Berridge, G R Park
}

TABLE I - Causes of fatal brain injury in 52 potential organ donors

\begin{tabular}{lc}
\hline Cause & $\begin{array}{c}\text { No of } \\
\text { cases }\end{array}$ \\
\hline Road traffic accident & 20 \\
Assault & 5 \\
Other trauma & 3 \\
Subarachnoid haemorrhage & 8 \\
Intracerebral haemorrhage & 9 \\
Cerebral neoplasm & 3 \\
Hypoxic brain injury & 3 \\
Hydrocephalus & 1
\end{tabular}

TABLE II-Complications of fatal brain injury in 52 potential organ donors ${ }^{\star}$

\begin{tabular}{ll}
\hline Complication & $\begin{array}{l}\text { No of } \\
\text { cases }\end{array}$
\end{tabular}

Diabetes insipidus

Hypotension

Hypothermi

Oliguria

Pulmonary oedema

More than one complication occurred in 22 cases.

\section{Department of \\ Anaesthesia,}

Addenbrooke's Hospital,

Cambridge CB2 2QQ

A Bodenham, FCANAES,

research registrar

J C Berridge, FCANAES,

research registrar

G R Park, FCANAES,

consultant in anaesthesia and

intensive care

Correspondence to:

Dr Park.

Br.Med J 1989;299:1009-10

\begin{abstract}
Organs for donation are in short supply in the United Kingdom, resulting in allegations that relatives of potential donors are not being asked for consent. Legislation on "required request" has been proposed to overcome this. The incidence, causes, complications, and patterns of organ donation in brain stem dead patients in one referral centre were studied over 12 months. Data were collected on all patients fulfilling criteria for brain stem death or considered suitable for donating organs after circulatory arrest. Forty two patients fulfilled the criteria for brain stem death, and in $\mathbf{1 0}$ further patients circulatory arrest occurred before formal testing was finished. The major causes of brain stem death were head injury (28) and intracranial haemorrhage (17). Consent to organ donation was obtained for 24 potential donors, and organs were donated by 23 of them. Twenty nine patients did not donate organs. The commonest reasons for failure to donate were medical unsuitability (13) and the coroner not releasing the body (eight). Consent was not sought in three cases, and the relatives refused consent in the remaining five.
\end{abstract}

This study suggests that required request will not considerably increase the supply of donor organs.

\section{Introduction}

Transplant surgeons have alleged that organs from many potential donors are not made available because of the reluctance of doctors to ask relatives to consent to donation and have therefore called for new legislation requiring clinicians to ask for consent. ${ }^{\prime}$ This assertion, however, was made without knowledge of the true incidence of brain stem death, the number of cases of brain stem death in which donation is possible, or how often the question of organ donation is raised and consent is refused. The often misquoted figure of 4000 potential donors a year in the United Kingdom was published in $1981^{2}$ but reported the number of patients in whom brain stem death was a possible diagnosis, not the number of organ donors.

The transplant teams at Addenbrooke's and nearby Papworth Hospitals are pioneers in organ transplantation. This generates much interest in the local and national media. Awareness of transplantation is thus high in the local population and the medical and nursing staff. It might therefore be expected that consent for organ donation would be considered by both medical staff and relatives more readily than in other centres. To determine the causes and complications of brain stem death in a major teaching hospital and to investigate whether required request would make an important difference to the numbers of potential donors failing to donate organs we prospectively studied for one year all patients admitted to the four intensive care units (general, paediatric, neurosurgical, and neurotrauma) at this hospital who were declared brain stem dead or considered suitable to donate organs after circulatory arrest.

\section{Subjects and methods}

From 18 November 1987 to 17 November 1988 all cases of brain stem death that occurred were reported to us. At diagnosis of brain stem death the following information was collected: age, general diagnosis, duration of artificial ventilation in the intensive care unit after the declaration of death, and number and type of organs donated. If organs were not donated by a potential donor then the reasons for this were examined and allocated to one of four categories: medical contraindications, consent not requested, consent denied by relatives, and consent denied by the coroner. In addition, any complications directly attributable to brain stem death were recorded. These included hypotension (systolic blood pressure $<80 \mathrm{~mm} \mathrm{Hg}$ without inotropic support), diabetes insipidus (urine output greater than $200 \mathrm{ml} / \mathrm{h}$ in patients not receiving diuretics and without other causes of polyuria), and hypothermia (temperature less than $35^{\circ} \mathrm{C}$ without warming).

\section{Results}

Forty two patients ( 25 male and 17 female) fulfilled the criteria for the diagnosis of brain stem death during the period of study. ${ }^{3}$ In 10 other patients (three male and seven female) circulatory arrest occurred before formal testing could be completed. The mean (SD) age of the subjects was $37 \cdot 3(22 \cdot 4)$ years (range $0.5-89$ years), and the mean duration of artificial ventilation after testing was 123 minutes (range 10-3070 minutes). The large range in duration of ventilatory support reflects the need in one instance to wait until relatives arrived from the Far East to give consent. The major causes of brain stem death were head injury (28 cases) and spontaneous intracranial haemorrhage (17 cases), with intracranial tumour, hypoxic brain injury, and hydrocephalus the remaining diagnoses (table I). All 52 subjects had at least one complication of brain stem dysfunction, with diabetes insipidus and hypotension occurring in most (table II).

Consent to organ donation was obtained for 24 of the potential donors, with organs being donated by 23 . One subject was found to have peritonitis at operation, which precluded organ retrieval. In four cases consent was restricted to donation of corneas, leaving 19 donors of solid organs, three of whom had had circulatory arrest. Table III shows the number of organs donated compared with the number for which consent to removal was granted. At the donor operation one kidney was found to have been traumatised previously and was not removed. Lack of a suitable recipient prevented the removal of a pair of kidneys, a liver, and three hearts. Three livers were not used because of a shortage of intensive care facilities for the recipients.

TABLE III-Number and type of organs donated by 19 donor compared with number of organs for which consent to removal given. In four further cases consent was restricted to corneal donation

\begin{tabular}{lccc}
\hline Organ & Consented & Donated & Not used \\
\hline $\begin{array}{l}\text { Kidneys } \\
\text { Liver }\end{array}$ & 38 & 35 & 3 \\
Liver-pancreas & $16^{\star}$ & $\left\{\begin{array}{l}9 \\
1\end{array}\right.$ & 6 \\
Heart & $\left\{16^{\star}\right.$ & $\left\{\begin{array}{l}7 \\
2\end{array}\right.$ & 7 \\
Heart-lung & 70 & 54 & 16
\end{tabular}

^Donor cannot donate liver and liver-pancreas or heart and heart-lung separately. 
TABLE IV-Causes of failure to donate for 29 potential organ donors

\begin{tabular}{lc}
\hline Cause of failure & $\begin{array}{r}\text { No of } \\
\text { cases }\end{array}$ \\
\hline Medical: & \\
Hypotension & 8 \\
Sepsis & 2 \\
Renal failure & 2 \\
Organ trauma & 1 \\
Consent: & \\
Denied by coroner & 8 \\
Denied by relative & 5 \\
Not requested & 3 \\
\hline
\end{tabular}

The age criteria for donations prevented the use of two livers and four hearts.

Twenty nine subjects failed to donate any organs (table IV). This was due to medical contraindications in 13 (profound hypotension, sepsis, trauma, or renal failure). In eight cases the injuries leading to brain stem death resulted in serious criminal charges being brought against another person. In such circumstances the coroner felt unable to grant permission for organ donation. There were five cases in which the relatives refused permission: in three they thought that the patient had "been through enough," in one the patient had expressed a wish not to donate organs, and in one the relatives had doubts about donation. Consent was not requested in only three.

\section{Discussion}

The shortage of organs for transplantation has been highlighted recently, accompanied by calls for changes in the law on consent to donation. ${ }^{14}$ In our study, though solid organs were donated from only 19 of 52 patients with brain stem death, in only three of the remaining 33 cases was consent for donation not requested. We suggest that failure to request donation after brain stem death is uncommon at our hospital. If this level of requesting donation is representative of that at most other centres then legislation to make request compulsory would not considerably increase the number of organs available for transplantation. Wakeford and Stepney, in a survey of attitudes to organ donation, concluded that coercive measures were less likely to increase the supply of donor organs than improved education of the public and the medical profession.

Sixteen organs were not used when consent to their removal had been granted because of lack of intensive care facilities or shortage of recipients matched for blood group and presence of cytomegalovirus. In this series organs from eight potential donors could not be used because the coroner would not release the body, a feature others have experienced with the procurator fiscal in Scotland (J D Miller, personal communication). The prevalence of traumatic causes of brain stem death suggests that this is a nationwide feature and is unlikely to change, though individual coroners and procurators fiscal have widely differing opinions on this subject, some releasing bodies when others would not.

Of concern is the large proportion (a quarter) of potential donors whose poor general condition rendered them unsuitable for donation. This, coupled with the high incidence of complications, means that such patients require careful medical and nursing care with particular attention to cardiovascular function. Perhaps by attention to these factors not only would absolute numbers of donors increase but there would also be an improvement in the condition of organs that are donated.

We thank our neurosurgical, neuroanaesthetic, and other medical colleagues and the Cambridge transplant coordinators for their cooperation with the collection of this information.

\footnotetext{
Chisholm GD. Time to end the softly softly approach on harvesting organs for transplantation. Br.Med F 1988:296:1419-20.

2 Jennett B, Hessett $C$. Brain death in Britain as reflected in renal donors. Br.Med f 1981;283:359-62.

3 Department of Health and Social Security Cudaveric organs for transplantation; a code of practice including the diagnosis of hrain death. London: HMSO, 1983 4 Rudge CJ. Consent for transplants. Br F Hosp Med 1987;38:93-4

5 Wakeford RE, Stepney R. Obstacles to organ donation. Br F Surg 1989:76: $435-9$.

(Accepted 9 August 1989,
}

\title{
Dipstick haematuria and bladder cancer in men over 60: results of a community study
}

\author{
J Philip Britton, Anthony C Dowell, Peter Whelan
}

Abstract

Objective-To investigate the prevalence and relevance of dipstick haematuria in a group of men in the community.

Design-Prospective study of elderly men invited to attend a health centre for urine screening as part of a health check.

Setting-An inner city health centre in Leeds.

Subjects -578 of 855 men aged $60-85$ responding to an invitation to participate.

Interventions-The subjects had their urine tested with a dipstick (Multistix) for the presence of blood and then tested their urine once a week for the next 10 weeks. Those with one or more positive test results were offered full urological investigation.

Main outcome measure-The prevalence of St James's University
Hospital, Leeds LS9 7TF J Philip Britton, FRCS, tutor and honorary registrar in urology

Anthony C Dowell, MRCGP, lecturer in general practice

Peter Whelan, FRCS,

consultant urologist

Correspondence to: Mr Whelan.

BrMed f 1989;299:1010-2 with appreciable urological disease. The introduction of less invasive methods of investigation, particularly flexible cystoscopy and ultrasonography, has made investigation of these patients simple and safe and makes screening for bladder cancer in the community more feasible.

\section{Introduction}

Urine dipsticks are widely used in health screening clinics,' in occupational health departments, and in routine clinical practice. ${ }^{2}$ Asymptomatic occult urinary bleeding is a common finding. Its prevalence in elderly men ranges from $4 \%$ to $13 \%$, ${ }^{3.6}$ and the reported incidence of associated urological abnormality varies from $40 \%$ to $100 \% .^{13.4}$ The need for and extent of investigation of such a finding, however, remains controversial. ${ }^{31011}$

The importance of investigating microscopic haematuria lies in the possibility of diagnosing urological malignancy at an early stage, especially bladder cancer. Bladder cancer is the fourth commonest malignancy in men, with an annual registration rate for men over the age of 60 in Yorkshire of 1.5 per 1000 (Yorkshire Regional Cancer Register). We report the results of a screening programme to investigate the prevalence and relevance of dipstick haematuria in a 